BNL-82173-2009-CP

\title{
Review of Recent Aging-Related Degradation Occurrences of Structures and Passive Components in U.S. Nuclear Power Plants
}

\author{
J. Nie, J. Braverman, C. Hofmayer, \\ Y-S. Choun, M.K. Kim, I-K. Choi \\ Presented at the International Conference on Nuclear Engineering \\ Brussels, Belgium \\ July 12-16, 2009 \\ Energy Science and Technology \\ Nuclear Energy and Infrastructure Systems Division \\ Brookhaven National Laboratory \\ P.O. Box 5000 \\ Upton, NY 11973-5000 \\ www.bnl.gov
}

\begin{abstract}
Notice: This manuscript has been authored by employees of Brookhaven Science Associates, LLC under Contract No. DE-AC02-98CH10886 with the U.S. Department of Energy. The publisher by accepting the manuscript for publication acknowledges that the United States Government retains a non-exclusive, paid-up, irrevocable, world-wide license to publish or reproduce the published form of this manuscript, or allow others to do so, for United States Government purposes.
\end{abstract}

This preprint is intended for publication in a journal or proceedings. Since changes may be made before publication, it may not be cited or reproduced without the author's permission. 


\section{DISCLAIMER}

This report was prepared as an account of work sponsored by an agency of the United States Government. Neither the United States Government nor any agency thereof, nor any of their employees, nor any of their contractors, subcontractors, or their employees, makes any warranty, express or implied, or assumes any legal liability or responsibility for the accuracy, completeness, or any third party's use or the results of such use of any information, apparatus, product, or process disclosed, or represents that its use would not infringe privately owned rights. Reference herein to any specific commercial product, process, or service by trade name, trademark, manufacturer, or otherwise, does not necessarily constitute or imply its endorsement, recommendation, or favoring by the United States Government or any agency thereof or its contractors or subcontractors. The views and opinions of authors expressed herein do not necessarily state or reflect those of the United States Government or any agency thereof. 


\title{
REVIEW OF RECENT AGING-RELATED DEGRADATION OCCURRENCES OF STRUCTURES AND PASSIVE COMPONENTS IN U.S. NUCLEAR POWER PLANTS
}

\author{
Jinsuo Nie, Joseph I. Braverman, Charles H. Hofmayer \\ Brookhaven National Laboratory \\ Upton, NY 11973-5000, USA \\ Email: inie@bnl.gov \\ Young-Sun Choun, Min Kyu Kim, and In-Kil Choi \\ Korea Atomic Energy Research Institute \\ Daejeon, 305-353, Korea
}

\begin{abstract}
The Korea Atomic Energy Research Institute (KAERI) and Brookhaven National Laboratory (BNL) are collaborating to develop seismic capability evaluation technology for degraded structures and passive components (SPCs) under a multi-year research agreement. To better understand the status and characteristics of degradation of SPCs in nuclear power plants (NPPs), the first step in this multi-year research effort was to identify and evaluate degradation occurrences of SPCs in U.S. NPPs. This was performed by reviewing recent publicly available information sources to identify and evaluate the characteristics of degradation occurrences and then comparing the information to the observations in the past. Ten categories of SPCs that are applicable to Korean NPPs were identified, comprising of anchorage, concrete, containment, exchanger, filter, piping system, reactor pressure vessel, structural steel, tank, and vessel. Software tools were developed to expedite the review process. Results from this review effort were compared to previous data in the literature to characterize the overall degradation trends.
\end{abstract}

\section{INTRODUCTION}

Aging-related degradation of SPCs is an important aspect in assessing the seismic safety of new and existing nuclear power plants (NPPs), especially in the process of periodic safety reviews and license renewal application (LRA) reviews. NUREG-1801 [1], " Generic Aging Lessons Learned (GALL) Report, " documents the technical basis for review of license renewal applications for U.S. NPPs. The GALL Report identifies aging management programs acceptable to the NRC for structures and components under varirous environments and aging effects/mechanisms. It was developed based on the review of over 500 age-related documents and was later revised to incorporate lessons learned from LRA reviews, public input, and industry comments. The GALL report provides technical guidance on aging degradation; however, it does not provide quantative information on actual agingrelated degradation characterisitcs found at U.S. NPPs. NUREG/CR-6679 [2] presents a quantitative assessment of age-related degradation occurrences of structures and passive components at U.S. NPPs. The development of NUREG/CR6679 was based on U.S. NPP Licensee Event Reports (LERs) for the period of 1985 to 1997, NRC generic correspondence, NUREGs, and industry reports. Following a similar approach to NUREG/CR-6679, this paper presents a review of recent degradation occurrences of SPCs in U.S. NPPs for the period 1999 to the present.

KAERI and BNL are collaborating to develop seismic capability evaluation technology for degraded SPCs. The goal of this collaborative research effort is to develop seismic fragility analysis methods that consider the potential effects of aging-related degradation of SPCs, and apply these results as input to seismic probabilistic risk assessment of NPPs. As the first step in this multi-year research effort, to better understand the status and characteristics of degradation of SPCs in NPPs, degradation occurrences of SPCs in U.S. NPPs were identified by reviewing recent publicly available information sources and the characteristics of these occurrences were evaluated and compared to the observations in the past. The aging characteristics considered in this effort included the component type, aging effects, aging mechanisms, identification method, evaluation method, plant name, date of occurrence, and other related information. 
This research focused on collecting and reviewing degradation occurrences in U.S. NPPs and identifying important aging characteristics needed for the seismic capability evaluations that will be performed in the subsequent evaluations in the years that follow. Ten categories of SPCs that are applicable and potentially risk significant in Korean NPPs were identified. These consist of anchorage, concrete, containment, exchanger, filter, piping system, reactor pressure vessel, structural steel, tank, and vessel. The documents reviewed included the U.S. NPP LERs for the period of 1999 to the present, recent NRC generic communications (Generic Letters, Bulletins, and Information Notices), and recent license renewal applications for a similar period of time. Software tools were developed to assist in obtaining more than 4,000 LERs from the NRC web site (ADAMS system) and in efficiently reviewing these LERs for aging-related degradation occurrences of SPCs. Results from this review effort were compared to previous data in the literature to characterize the overall degradation trends. This paper presents brief discussions of the suitability of the reviewed documents for identification of degradation occurrences, statistics of the degradation occurrences in terms of various parameters, results of the trending analysis, and the related insights reached from this research effort [3].

\section{REVIEWED COMPONENTS}

NUREG/CR-6679 [2] developed a list of 18 categories of SPCs that are within the scope of the NRC License Renewal Rule 10 CFR Part 54 and the Maintenance Rule 10 CFR 50.65. By combining this list of 18 SPC categories and a list of potentially risk significant SPCs provided by KAERI, ten categories of SPCs were selected for use in this study. Eight component categories from NUREG/CR-6679, namely the cable tray systems, conduit systems, cooling tower, electrical conductors, HVAC duct, insulation/seal, structural seismic gap, and water-control structures, are not included in this search effort because they are not considered to be applicable/risk significant according to the component list provided by KAERI.

The subcomponents in each of the ten categories are described below:

Anchorage: anchorage covers all structural components that serve as a connection between a concrete element and a piece of equipment. Anchorages include embedded anchors, expansion anchors, grout (used beneath baseplates), and steel embedments.

Concrete: the concrete category includes reinforced concrete buildings; water intake structures; pump house; underground structures; concrete walls, floors, ceilings, mats, and foundations; canals; fuel pools; pits; pedestals; prestressed concrete structures; and manholes. It also includes masonry walls and block walls.

Containment: containment is a special type of structure in NPPs used as a final barrier to prevent the release of radioactive materials to the environment following a postulated accident that may occur inside the containment. Therefore, the containment is not categorized as either concrete or structural steel components. The containment category includes the steel shell or concrete shell, prestressing system if applicable, penetrations, torus (if applicable), bellows, liners, and supports. The prestressing system includes tendons, tendon anchorages, and grease used in the tendon conduits to prevent degradation of the tendons.

Exchanger: the exchanger category includes steam generator, heat exchanger, condenser (including ice condensers used in the design of some US plants), and their supports.

Filter: filters include mechanical \& HVAC - screens, separators, strainers, absorbers, relevant supports, and housings. It should be noted that the subcomponents for filters do not include regular maintenance items which are examined or replaced on a regular basis.

Piping system: piping systems include piping, underground piping, fittings, small bore piping \& tubing, sleeves, and pipe supports. Hydraulic or mechanical assemblies of snubbers are not considered since they are active components and subject to periodic inspection and maintenance if needed.

RPV: subcomponents of reactor pressure vessels (RPVs) include the shell, internals, passive components for control rod drive mechanisms (CRDMs), and relevant supports. RPVs are distinguished as an individual component from other vessels because of their unique and important roles in nuclear power plants.

Structural steel: the structural steel category includes steel frames, trusses, platforms, supports, bolts, nuts, studs, fasteners, liners, doors, covers, hatches, and support to all types of equipment.

Tank: tanks are those vessels that are subject only to atmospheric pressure.

Vessel: vessels are pressurized, and include subcomponents such as the pressurizer, other pressurized vessels, and their supports.

It should be noted that the subcomponents in some of these component categories are not always exactly the same as those used for NUREG/CR-6679. In particular, the penetrations under the containment category and the piping, fittings, small bore piping, tubing, and sleeves under the piping system category, were removed from further review (after some initial tabulation) in NUREG/CR-6679 because aging of these components were being addressed by other existing NRC programs. In addition, the 105 degraded piping system components reported in NUREG/CR-6679 were only a part of all degradations that actually occurred, because the 
total number of piping system degradation occurrences were found to be too numerous. In this paper, the tabulation of the degradation occurrences using LERs was more thorough in the sense that none was intentionally discarded. These differences were taken into account in the statistical comparison and the trending analysis.

Degradation occurrences included in this report do not necessarily correlate to the number of degraded elements at a specific plant and date. If several degraded elements are found at the same plant and the same date, they are grouped into one degradation occurrence if they are the same subcomponent.

\section{REVIEW OF RECENT LERS}

\section{Review Methodology}

In additon to their public availablility, the LERs were selected for the following reasons: standardized requirement in accordance with 10 CFR 50.73 [4], continuous in time, completeness of information, good coverage of significant events, well formatted, and easy accessibility. Since January 1,1984 , an LER is required by 10 CFR 50.73 to be submitted within 60 days after the occurrence of a significant event, following an immediate notification (required by $10 \mathrm{CFR}$ 50.72 [5]). Each LER and its revisions are generally required to address specific events and plant conditions. Unrelated events or conditions, including cases of the same or similar components but different causes or separate events/activities, should be reported in different LERs. Voluntary LERs are encouraged to be submitted even if the events are not required by 10 CFR 50.73 and other requirements, but are believed by the licensee to be safety-significant. LERs have been used by the NRC staff in NUREG-1022 to study potentially generic safety problems, and assess trends and patterns of operational experience, as well as in other applications [6]. For each of 14 reportable items, NUREG-1022 provides detailed description, discussion, and many application examples.

LERs are also required by 10 CFR 50.73 to contain a brief abstract; a clear, specific, and narrative description of the event; an assessment of the safety consequences and implications of the event; corrective actions; and references to any previous similar events. In addition, LERs start with a signed cover letter and usually have a very instructive title. Most LERs utilize NRC Forms 366/366A/366B, which include information such as facility name, docket number, event date, LER number, report date, etc. Compared to other sources of information as described in NUREG/CR-6679, LERs have the advantage of information completeness and rule-based format, which can facilitate automation in their processing.

For review of LERs under this reserach effort, a degradation occurrence record (DOR) was developed for each component where degradation was identified. DORs are stored in a database. Each DOR includes the following fields in the database: ML number, LER reference number, Event Date,
Plant Name, Docket Number, System, Component, Subcomponent, Aging Effects, Aging Mechanisms, How Identified, Evaluation Method, and Repair method.

The LERs used in NUREG/CR-6679 were processed through the Sequence Coding \& Search System (SCSS) that was created and maintained for the NRC by the Nuclear Operations Analysis Center at the Oak Ridge National Laboratory, and covered the period of 1985 to 1997. Unfortunately, SCSS is not accessible anymore and development of a system similar to SCSS would require a sizable effort beyond the available resources for this project. Therefore, the identification and review process of recent LERs is based on the NRC ADAMS system. The NRC ADAMS systems include all image and text documents that the NRC has made public since November 1, 1999, as well as bibliographic records (some with abstracts and full text) that the NRC made public before November 1999. In ADAMS system, any document can be uniquely identified by its accession number (MLxxxxxxxxx).

Highly sophisticated search methods are provided by the NRC ADAMS system. Using the advanced search method with "LER" as the document type field, a total of 4323 LERs had been found through the ADAMS Publicly Available Records System (PARS), as of 04/16/2008. By using different sets of keywords for each component category, one could either retrieve a reasonable number of LERs but leave the coverage in question, or achieve a high confidence in population coverage but retrieve so many LERs that the total number of reviewed LERs for all ten component categories could be much more than 4323. This makes the development of appropriate keywords difficult. In the meantime, developing the keyword list required repetitive accesses of the ADAMS system to check the appropriateness of the returned LER list and consequently represented a sizable effort.

Instead of reviewing directly through the online ADAMS system, in-house software tools were developed to expedite the review process. These tools were used to retrieve the 4323 HTML files, convert these HTML files to pure text files, and help review the LERs by color-coding different parts of the LERs and other document enhancements [3].

\section{Result Assessment}

A total of 223 DORs were identified from the LERs for the period of 1999 to the present (4/16/2008), including just a few from 1998 as well. Figure 1 shows the distribution of the SPC degradation occurrences by component categories, with the number of the degradation occurrences annotated over the bars. As would be expected, the piping systems have the most degradation occurrences reported in the LERs, about $36 \%$ of the total DORs. Exchangers and RPVs have the next two largest number of degradation occurrences, representing about $22 \%$ and $17 \%$ of the total DORs, respectively. The other seven component categories represent less than $25 \%$ of the total DORs; they are vessels, filters, containments, structural steel, tank, concrete, and anchorage in descending order of the 
number of degradation occurrences. It should be noted that the number of degradation occurrences for a particular category is also a function of the quantity of components in that category that is present at a plant. So for example, the number of degradation occurrences for piping was expected to be large, because there are many piping systems at a NPP and many of these piping systems can be quite long.

The total number of DORs for structural type components, i.e., containments, structural steel, concrete, and anchorages, is only 18 , about $8 \%$ of all DORs. However, this does not necessarily indicate that there have been fewer degradations occurring in these structures. Rather, it is because of the nature of the structural degradation and the nature of LER reporting requirement that are judged to result in fewer instances of degradation. As described previously, LERs report any degradation situations that seriously affect the plant safety or result in any unanalyzed conditions that could significantly compromise the plant safety. The events reported in LERs are often from operating experiences. Structural degradations usually have less immediate impact on plant safety, and therefore, are less likely to be observed and reported in LERs. However, structural degradations can be significant risk factors to plant safety when a severe environmental event, for example, a large earthquake, occurs. Many structural degradations can be found in the literature that involved results from special inspection efforts. For example, NUREG-1522 provides useful information on structural degradations obtained from walkdowns conducted at six older vintage plants [7].

To evaluate the possible trends in degradation occurrence data, the DORs in the past decade (approximately 1999 to 2008 collected in this study) and those reported in NUREG/CR-6679 (approximately 1985 to 1997) were compared. In order to make a sound comparison, a few differences between the current data collection using the recent LERs and those reported in NUREG/CR-6679 should be noted. These are highlighted in the following:

1. Difference in Information Sources: unlike the current set of data collected in this study which rely on LERs 19992008, NUREG/CR-6679 covered a larger set of information sources, which included LERs 1985-1997, NUREGs, NRC/IE Information Notices, Correspondences, Generic Letters, NRC Bulletins, IR Circulations, SECY documents, and other publicly available documents.

2. Difference in LER retrieval methods: one-by-one evaluation for LER 1999-2008 versus computer based search for LER 1985-1997 through SCSS.

3. Difference in component lists: 10 component categories for current collection versus 18 component categories for NUREG/CR-6679.

4. Difference in subcomponent lists: all SPCs for current collection versus reduced scope for NUREG/CR-6679 (e.g., elimination of piping, fittings, small bore piping \& tubing, sleeves, penetrations, etc.).

Figure 2 shows the distributions of the degradation occurrences by components for three series of data: LER 1999-2008, NUREG/CR-6679 (containing LERs 1985-1997 and other sources), and NUREG/CR-6679 LER 1985-1997. The bar chart is presented in the same order of components as reported in NUREG/CR-6679. Similarly, Figure 3 shows a normalized version of the same figure with the total numbers of DORS in each series as the basis. Considering LER 19992008 and NUREG/CR-6679, exchangers, piping system, and RPVs are the first three categories with the greatest percentage of degradation occurrences. Since the piping system DORs for LER 1985-1997 were determined to be very large and did not include all of the occurrences in the SCSS database, the actual number of DORs of piping system for LER 1985-1997 is artificially low which is reflected in the figures. These figures also show that filters were the second largest category using LER 1985-1997. Both LER data series confirm the observation in the previous section that LERs do not report many structural DORs, especially containment, concrete, and anchorage; but that is not to say that they are potentially less significant in terms of plant risk.

Figure 4 shows the distribution comparison of the SPC degradation occurrences over time, with the top figure showing the two series from NUREG/CR-6679 and with the bottom figure showing the series representing LER 19992008. First of all, the strong correlation over the years between the two series from NUREG/CR-6679 indicates that LER 1985-1997 represent a significant portion of the NUREG/CR-6679 data. Regardless of the partial years 1997, 1998, and 2008, the yearly DORs varies somewhat in cycles, which might correspond to inspection intervals that often are scheduled at refueling or are required by special NRC mandatory inspection requirements. On a yearly basis, there appear to be slightly more DORS from LER 1998-2008 than from LER 1985-1997. This observation may suggest that more degradation occurrences occured as plants are getting older, but may also be due to the differences in reviewing LERs.

Other comparisons showed that cracking was indicated by all three data series as the most predominant aging effect for steel components (more precisely metal components), and stress corrosion cracking was the major aging mechanism. The reactor coolant system was found to be the most vulnerable system as indicated by all three data series. More detailed comparison and trending analysis information can be found in Reference 1.

\section{REVIEW OF RECENT NRC GENERIC COMMUNICATIONS}

Generic communications are publicly available documents through the NRC web site. Generic communications are the NRC's primary method of 
communicating a common need or resolution approach to an issue or providing guidance on issues pertaining to a matter of regulatory interest. Generic communications also allow the NRC to communicate and share industry experiences and send information to specific classes of licensees and interested stakeholders. The type of generic communication issued is determined during NRC evaluations of the operating nuclear industry and regulatory activities. Once issued, a generic communication is placed in the ADAMS system as an official NRC record. The generic communication is then electronically sent out to subscribers and posted to the NRC external Web site.

The NRC generic communications reviewed include Generic Letters (GLs), Bulletins (BLs), and Information Notices (INs). GLs are NRC communications to licensees for the purpose of transmitting important information and usually require action or response. BLs address significant issues of great urgency and usually require action or response. INs relate to safety, safeguards, or environmental issues on which licensees consider action as appropriate.

Since these documents may not include all information required by a DOR or may include duplicate DORs with respect to LERs, the degradation information obtained from NRC generic communications is evaluated and described separately in this paper. Similar to the review effort of LERs, the focus of this study was on recent GLs, BLs, and INs, within the same period of 1997 through the first part of 2008 . Based on the available communications on the NRC web site, the actual review periods were 1997 to 2006 for GLs, 2001 to 2004 for BLs, and 1998 to 2007 for INs. A total of 46 generic communication documents were reviewed, including 7 GLs, 6 BLs, and 33 INs.

Table 1 summarizes for each type of generic communication the number of generic communications that address a particular component/subcomponent, and Table 2 aggregates the results in Table 1 by removing the types of generic communications. It should be noted that the number of generic communications addressing a component is different from the number of degradation occurrences because one generic correspondence may refer to multiple events with regard to one component. As can be seen from Table 2, steam generators (exchangers), RPVs, and piping systems are the top three components with the greatest number of generic correspondences, which are about $28 \%, 28 \%$, and $15 \%$ of the total 46 documents. These numbers constitute a total of $71 \%$, which is very close to the $75 \%$ found using LERs for the same three component categories. There were 6 generic correspondences on structural type components (containment, concrete, spent fuel pool), which is about $13 \%$ of the total number of reviewed generic correspondences. This ratio is somewhat higher than the $8 \%$ as determined using LERs, indicating that generic communications addressed more structural type components.

\section{REVIEW OF RECENT LRAS}

License Renewal Applications (LRAs) were also reviewed under this study because they provide useful information about aging degradation of SPCs. These applications are required to include information about aging by regulations which cover the submittal of LRAs. These regulations specifically require applicants to describe their operating experience regarding age-related degradation for the various SPCs.

The Atomic Energy Act and NRC regulations limit commercial power reactor licenses to an initial 40 years but also permit such licenses to be renewed for an additional 20 years. This original 40 -year term for reactor licenses was based on economic and antitrust considerations - not on limitations of nuclear technology. Due to this selected period, however, some structures and components may have been engineered on the basis of an expected 40-year service life. Since the expense of design and construction of NPPs has been so great, it is generally much more cost effective to extend the operating life of a NPP beyond the 40-year license given to plants. Therefore, the NRC has established a timely license renewal process and clear requirements for renewing the operating license of NPPs. These requirements are codified in 10 CFR Part 54, "Requirements for Renewal of Operating Licenses For Nuclear Power Plants" [8] and 10 CFR Part 51, "Environmental Protection Regulations for Domestic Licensing and Related Regulatory Functions" [9]. These requirements assure safe plant operation for the extended plant life. Renewal of license, when approved, is granted for an additional 20 years.

At the NRC website, there are 24 completed (reviewed and approved) applications for license renewal. There are also 12 LRAs under review at the time that this study was performed. Since each LRA is quite large and the total number of LRAs are too numerous to review in the current study, two LRAs were selected for review in this study. The criteria used for selection of the two LRAs are (1) one of each PWR \& BWR, (2) recent LRA - more likely to reflect knowledge gained from prior LRA submittals \& comments from NRC, (3) more complete information on operating experience, and (4) more detailed. Using these criteria, the two LRAs selected are Palisades (PWR) and Point Beach Units 1 \& 2 (BWR). Detailed review of these two LRAs included summaries of the Aging Management Programs and operating experiences that cover industry-wide observations and plant specific issues. The review of these LRAs qualitatively showed that degradation in components related to piping systems, RPVs, and exchangers occurred more often than the other components being studied. This observation is consistent with the results from the review of LERs as expected because the industry and plant-specific operating experiences on aging in the LRAs were most likely already in the LERs that the plant(s) submitted in the past. 


\section{CONCLUSIONS}

This paper provides an overview of a joint research effort by BNL and KAERI on collecting and reviewing degradation occurrences in the U.S. NPPs and identifying important aging characteristics needed for the seismic capability evaluations. The review was conducted using recent LERs, GLs, BLs, INs, and LRAs.

A total of 223 recent DORs were identified for the ten component categories since 1999. Piping systems, exchangers, and RPVs were found to have the most degradation occurrences reported in LERs, representing about 36\%, 22\%, and $17 \%$ of the total DORs, respectively. It was also found that LERs do not report a significant number of structural type components, such as containments, structural steel, concrete, and anchorages. However, this does not indicate in any way that structural degradations are of less significance to plant safety. The slightly higher degradation rate identified using more recent LERs reflects the observation that as plants age they generally show somewhat more degradation occurrences. Cracking was found to be the most predominant aging effect. Stress corrosion cracking was the most significant aging mechanism. The system that was most vulnerable to degradation is the reactor coolant systems.

Review of recent GLs, BLs, INs, and LRAs qualitatively confirmed comparable findings to those using LERs.

\section{ACKNOWLEDGEMENT}

This research was supported by the Mid- and Long-Term Nuclear Research \& Development Program of the Ministry of Education, Science and Technology, Korea, which is gratefully acknowledged.

\section{DISCLAIMER NOTICE}

The findings and opinions expressed in this paper are those of the authors, and do not necessarily reflect the views of Brookhaven National Laboratory or the Korea Atomic Energy Research Institute.

\section{REFERENCES}

1. NUREG-1801, "Generic Aging Lessons Learned (GALL) Report," Rev. 1, U.S. Nuclear Regulatory Commission, Washington, DC, September, 2005.

2. Braverman, J.I., C.H. Hofmayer, R.J. Morante, S. Shteyngart, and P. Bezler (2000), "Assessmesnt of agerelated degradation of structures and passive components for U.S. nuclear power plant," NUREG/CR-6679, Brookhaven National Laboratory.

3. Nie, J., J.I. Braverman, C.H. Hofmayer, Y.S. Choun, M.K. Kim, and I.K. Choi (2008), "Identificaiton and assessment of recent aging-related degradation occurrences in U.S. nuclear power plants, " BNL Report81741-2008, KAERI/RR-2931/2008, Brookhaven National Laboratory.

4. 10 CFR 50.73, Licensee Event Report System.

5. 10 CFR 50.72, Immediate Notification Requirements for Operating Nuclear Power Reactors.

6. NUREG-1022, "Event reporting guidelines 10 CFR 50.72 and 50.73," Rev. 2, U.S. Nuclear Regulatory Commission, Washington, DC, 20555, October 2000.

7. NUREG-1522, "Assessment of Inservice Condition of Safety-Related Nuclear Plant Structures," by H. Ashar and G. Bagchi, U.S. Nuclear Regulatory Commission, Washington, D.C., June 1995.

8. 10 CFR Part 54, Requirements for Renewal of Operating Licenses for Nuclear Power Plants.

9. 10 CFR Part 51, Environmental Protection Regulations for Domestic Licensing and Related Regulatory Functions. 
TABLE 1 SUMMARY OF DEGRADATION INFORMATION BY GENERIC COMMUNICATIONS

\begin{tabular}{|c|c|c|}
\hline $\begin{array}{c}\text { Generic } \\
\text { Correspondence }\end{array}$ & Component / Subcomponent & $\begin{array}{c}\text { Number of Generic } \\
\text { Correspondences on this } \\
\text { Component }\end{array}$ \\
\hline \multirow[t]{4}{*}{ Generic Letter } & Steam Generators & 4 \\
\hline & Strainer - Sump Pump Screens & 2 \\
\hline & RPV - CRD nozzles \& other penetrations & 1 \\
\hline & & Subtotal $=7$ \\
\hline \multirow[t]{4}{*}{ Bulletin } & RPV - head penetrations, \& coolant boundary & 4 \\
\hline & Strainer - Sump Pump Screens & 1 \\
\hline & Pressurizer \& steam space piping connection & 1 \\
\hline & & Subtotal $=6$ \\
\hline \multirow[t]{10}{*}{ Information Notice } & Steam Generators & 9 \\
\hline & RPV - nozzles & 8 \\
\hline & Piping & 7 \\
\hline & Containment & 3 \\
\hline & Concrete & 2 \\
\hline & Pressurizer & 2 \\
\hline & Spent fuel pool - liner & 1 \\
\hline & Equipment - boric acid leakage onto & 1 \\
\hline & & Subtotal $=33$ \\
\hline & & Total $=46$ \\
\hline
\end{tabular}

TABLE 2 SUMMARY OF DEGRADATION BY COMPONENTS

\begin{tabular}{|c|c|}
\hline Component & $\begin{array}{c}\text { Number of Generic } \\
\text { Correspondences }\end{array}$ \\
\hline Steam Generators & 13 \\
\hline RPV & 13 \\
\hline Piping & 7 \\
\hline Strainer - Sump Pump Screens & 3 \\
\hline Pressurizer & 3 \\
\hline Containment & 3 \\
\hline Concrete & 2 \\
\hline Spent Fuel Pool & 1 \\
\hline Equipment - boric acide leakage onto & 1 \\
\hline & Total $=46$ \\
\hline
\end{tabular}




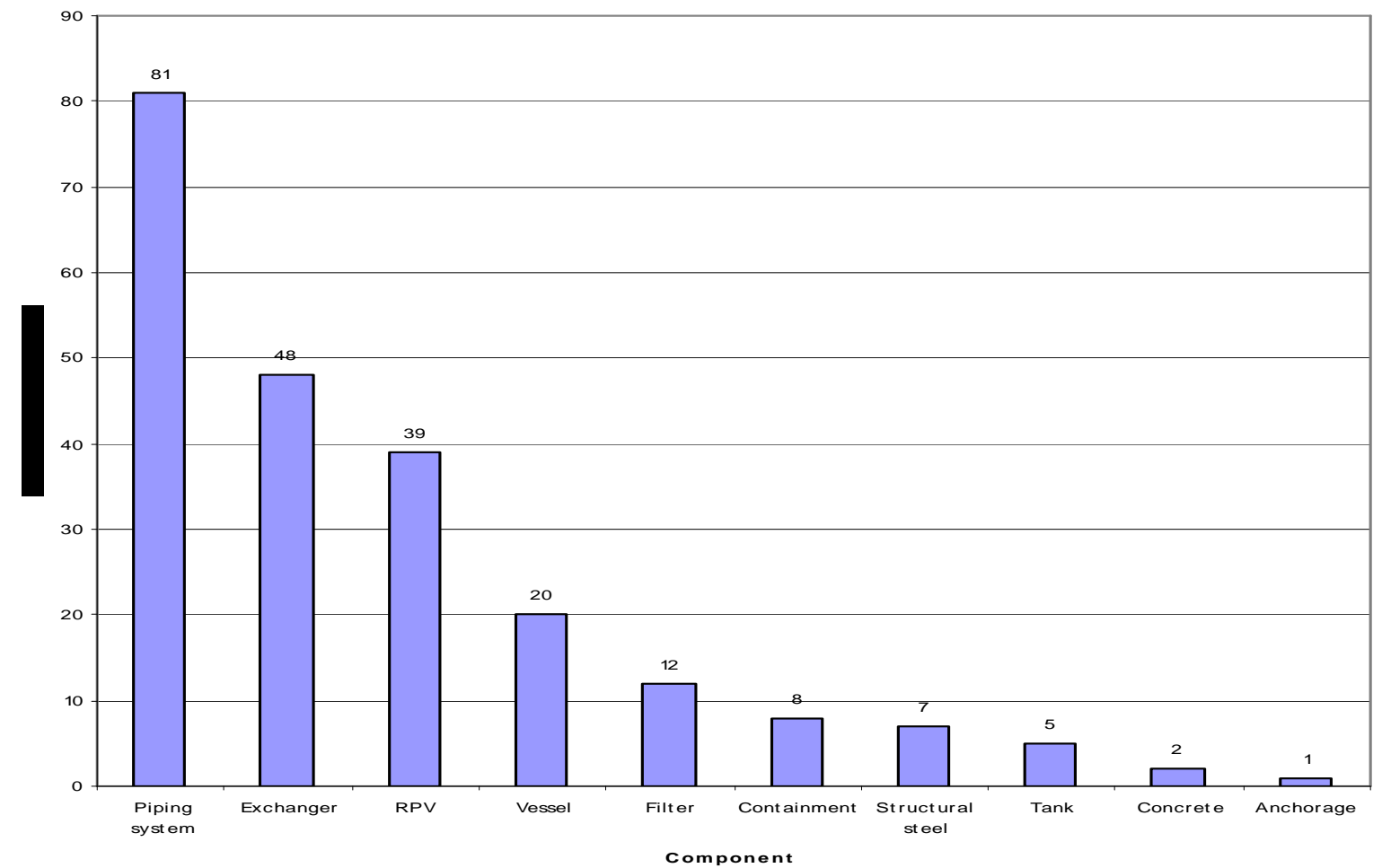

FIGURE 1 DISTRIBUTION OF SPC DEGRADATION OCCURRENCES OVER COMPONENT CATEGORY

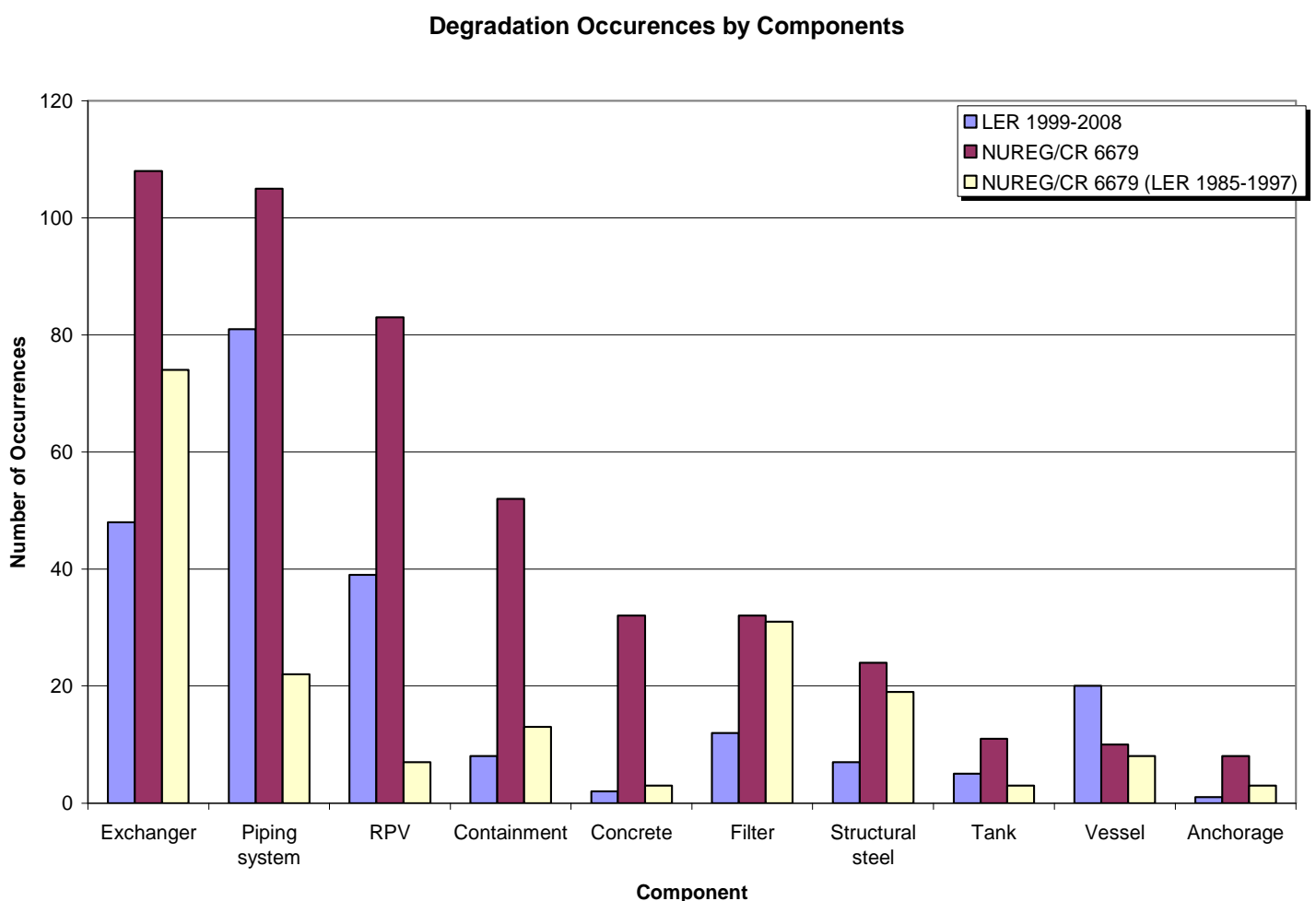

FIGURE 2 DISTRIBUTION COMPARISON OF SPC DEGRADATION OCCURRENCES OVER COMPONENT 


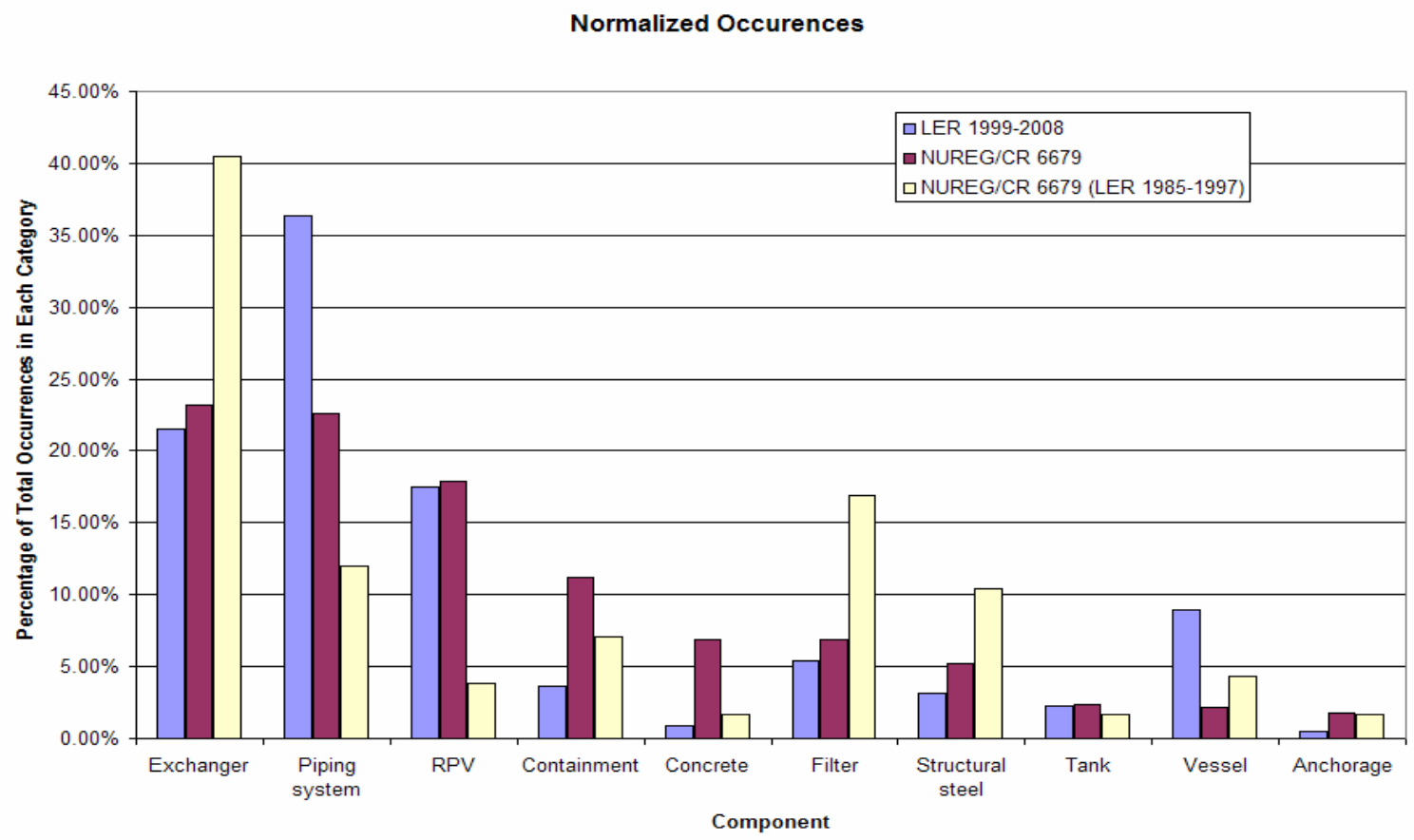

FIGURE 3 COMPARISON OF NORMALIZED DISTRIBUTION OF SPC DEGRADATION OCCURRENCES OVER COMPONENT 

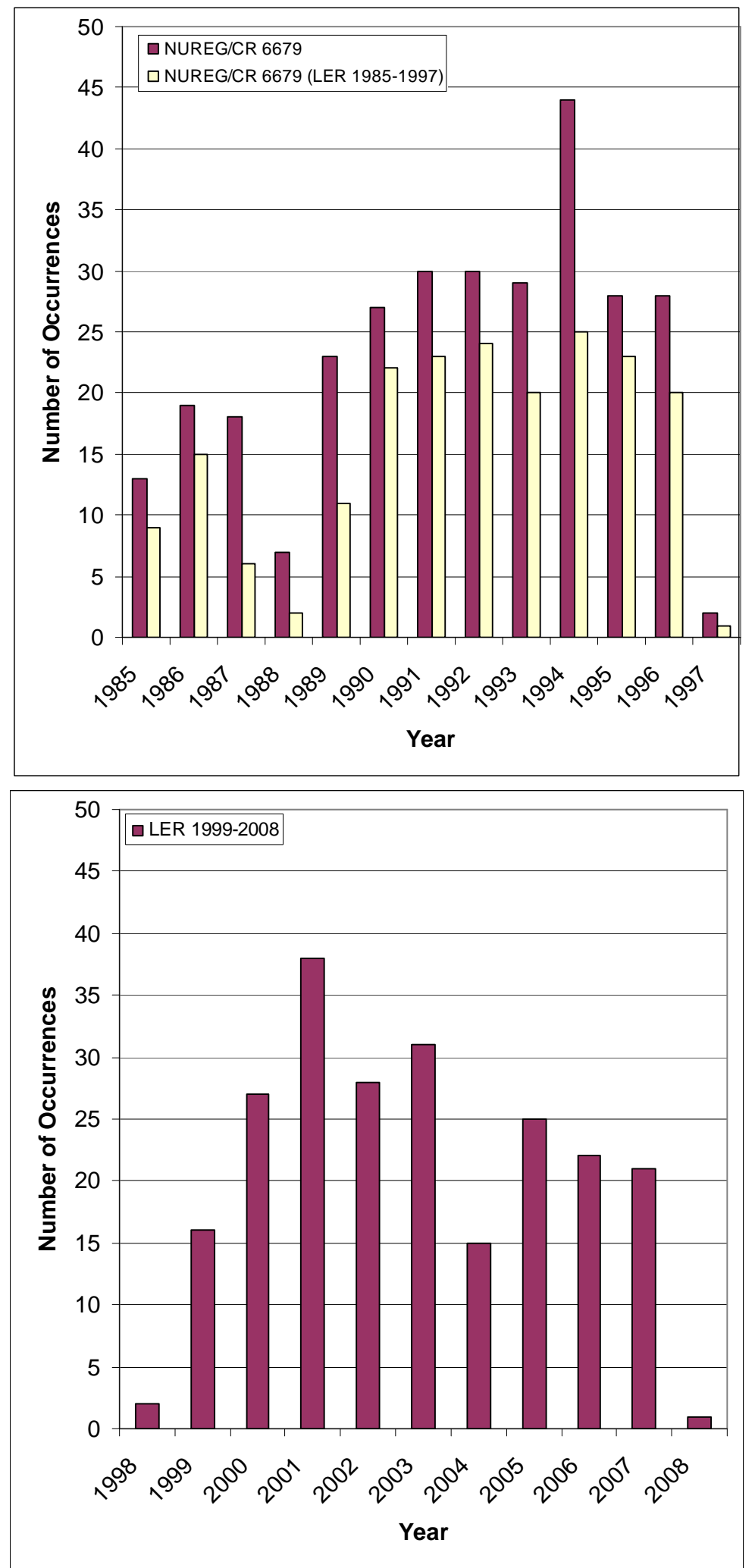

FIGURE 4 DISTRIBUTION COMPARISON OF SPC DEGRADATION OCCURRENCES OVER TIME 